\title{
The Effect of Alcohol Consumption on the Academic Performance of Undergraduate Students
}

\author{
Idoko Joseph Onyebuchukwu ${ }^{1,}$, , Muyiwa Adeniyi Sholarin ${ }^{2}$, Agoha Benedict Chico Emerenwa ${ }^{2}$ \\ ${ }^{1}$ Counselling Centre, Covenant University, Ota, Ogun State, Nigeria \\ ${ }^{2}$ Department of Psychology, School of Human Resource Development, College of Leadership \& Development Studies, Covenant University, \\ Ota, Ogun State, Nigeria
}

\section{Email address:}

joseph.idoko@covenantuniversity.edu.ng (I. J. Onyebuchukwu), josephidoko11@gmail.com (I. J. Onyebuchukwu), solarinadeniyi@gmail.com (M. A. Sholarin), ben.agoha@covenantuniversity.edu.ng (A. B. C. Emerenwa)

\section{To cite this article:}

Idoko Joseph Onyebuchukwu, Muyiwa Adeniyi Sholarin, Agoha, Benedict Chico Emerenwa. The Effect of Alcohol Consumption on the Academic Performance of Undergraduate Students. Psychology and Behavioral Sciences. Vol. 4, No. 4, 2015, pp.147-153.

doi: $10.11648 /$ j.pbs.20150404.12

\begin{abstract}
Most people know that academic performance generally refers to how well a student is accomplishing his or her tasks and studies, but there are numbers of factors that determine the level and quality of students' academic performance. This study investigated the effect of alcohol consumption on the academic performance of undergraduate students. A survey research design was used. A pilot study was carried out with 30 students to validate and determine the psychometric properties of the questionnaires used in this study. Total of 200 respondents, 114 male and 86 females with ages ranging between 13 and 25 years participated in this study. Three hypotheses were tested using Pearson $r$, T-test, Anova, and simple regression analysis. The result revealed that there is a significant relationship between alcohol consumption and academic performance $\left(\mathrm{R}^{2}=0.74, \mathrm{P}<. \mathrm{O} 5\right)$, there is a significant difference in academic performance of students that drink alcohol and those that do not $\left(\mathrm{R}^{2}=12.22, \mathrm{P}<.05\right)$, there is a significant effect of alcohol consumption on academic performance $\left(\mathrm{R}^{2}=4.474, \mathrm{P}<.05\right)$. The study has recommendations.
\end{abstract}

Keywords: Alcohol, Consumption, Academics, Performance, Undergraduates

\section{Introduction}

In educational institutions, success is measured by academic performance, or how well a student meets standard set out by institution. As career competition grows ever fiercer in the working world, the importance of students doing well in school has caught the attention of parents, and employers. Education is not the only road to success in the working world, much effort is made to identify, evaluate, track and encourage the progress of students in schools. Parents care about their child's academic performance because they believe that good academic results will provide more career choices and job secutity. Perfomance in school is evaluated in a number of ways. For regular grading, students demonstrate their kowledge by taking written and oral tests, performing presentations, turning in home work and participating in class activities and discussions. Academic achievement or (academic) performance is the outcome of education The extent to which a student, teacher or institution has achieved their educational goal. Academic achievement is commonly measured by examinations or continuous assessment but there is no general agreement on how it is best tested or which aspects are most important — procedural knowledge such as skills or declarative knowledge such as facts. (majkut@fas.harvard.edu). Students academic gain and learning performance is affected by numerous factor including gender, age, teaching faculty, students schooling, father/guardian social economic status, what they consume, residential area of students, medium of instructions in schools, tuition trend, daily study hour and accommodation as hostelries or day scholar. Many researchers conducted detailed studies about the factors contributing to students' performance at different study levels. Graetz (1995) suggested that a student's educational success is contingent heavily on social status of student's parents/ guardians in the society. Considine and Zappala (2002) noticed the same that parent's income or social status positively affects the student test score in examination. According to Minnesota (2007) "the higher education performance is depending upon the 
academic performance of graduate students. Durden and Ellis quoted Staffolani and Bratti, (2002) observed that "the measurement of students previous educational outcomes are the most important indicators of students future achievement, this refers that as the higher previous performance is, better and will predict the student's academic performance in future . Lot of studies have been conducted in the area of students achievement and these studies identified and analyzed the number of factors that affect the academic performance of the student at school, college and even at university level. Their findings identified students' effort, previous schooling, parent's educational background, family income, self motivation of students, age of student, learning preferences and entry qualification of students as important factors that have effect on student's academic performance in different setting. The utility of these studies lies in the need to undertake corrective measures that improve the academic performance of undergraduate students. It is generally assumed that the students who showed better or higher performance in the starting classes of their studies also performed better in future academic years at degree level. Everyone can be surprised with this assumption if it could be proved scientifically. From the last two decades it has been noticed significantly that there is great addition in research literature and review material relating to indicators of academic achievement with much emphasis on this dialogue, whether traditional achievement measures of academic performance are best determinants of future academic gain at university or higher level or innovative measures. However, it is also observed that many of the researchers do not agree with this view point or statement. Reddy and Talcott (2006) disagrees with these assumptions that future academic gains are resolute by preceding performance. In their research on the relationship between previous academic performance and subsequent achievement at university level, they found that students learning or studying at graduate level and the score secured did not predict any academic achievement at university level. They also cited Pearson and Johnson (1978) who observed that on the whole grade association of only 0.28 graduate level marks and university degree achievement was recorded. Parent's socio-economic condition, which includes parents' academic and professional qualification, revenue and occupational affiliation, is also associated with academic gain of students. The results of many studies confirmed that academic achievement of students is contingent upon parent's socio-economic condition. So the students belonging to higher socioeconomic backgrounds will perform better than other students associated with low socioeconomic backgrounds. "Social and economical status of student is generally determined by combining parents' qualification, occupation and income standard" (Jeynes, 2002). Among many research studies conducted on academic achievement, it is not very surprising to observe that Socioeconomic status is one of the main elements studied while predicting academic performance. Graetz (1995) conducted a study on socio-economic status of the parents of students and concluded that the socio economic background has a great impact on student's academic performance, main source of educational imbalance among students and student's academic success contingent very strongly on parent's socio economic standard. Considine and Zappala (2002) also having the same views as Graetz (1995), in their study on the influence of social and economic disadvantage in the academic performance of school students noticed, where the parents or guardians have social, educational and economical advantage definitely strengthen the higher level success in future. But it is also noted that these parents make available sufficient psychological and emotional shore up to their children by providing good educational and learning environment that produce confidence and the improvement of skills needed for success. On other hand Pedrosa et.al (2006) in their study on social and educational background pointed out those students who mostly came from deprived socio-economic and educational background performed relatively better than others coming from higher socioeconomic and educational area. They named this phenomena educational elasticity. It is obvious and true that the criteria for categorizing socio-economic standard in different countries are different depending of their norms and values. The criteria for low socioeconomic status for developed country will be different from the criteria of developing nations and same will be in the case of developing and under developing countries. "The total income of families, monthly or annually and their expenditures also put a great effect on the learning and academic opportunities accessible to youngsters and their chances of educational success. Furthermore, he also pointed that due to residential stratification and segregation, the students belonging to lowincome backgrounds usually attend schools with lower funding levels, and this situation reduced achievement motivation of the students and high risk of educational malfunction in future life endeavors" (Escarce, 2003).

Alcohol is a colorless, volatile, flammable liquid which is the intoxicating constituent of wine, beer, spirits and other drinks. Alcohol is no ordinary commodity but a drug that can be depended upon (Gureje et al, 2007) Production and consumption of alcohol in the modern Nigeria is on the increase and the volume is highly unrecorded due to illegal and local productions and the paucity of data on the legality of production (Chikere \& mayowa 2011). World health organization (2004) ranked Nigeria among the thirty nations with the highest per capita consumption of alcohol worldwide. The new drinking norms that have evolved are drinking competitions among youths. Bar owners, brewery's representatives set out prizes for the fastest drinkers and the winner is judged based on the quantity consumed (Odejide et al, 1987, 1999, 2006). In Nigeria there is star trek, gulder ultimate search and a host of others. In the universities there is a group known as kegite club which uses palm wine as holy water. There can be lingering cognitive deficits up to 48 hours after a night of drinking. Heavy drinking by students can lead to positive blood alcohol levels the next day, affecting whether or not they even get up for class and, if they do, the quality of how information is processed and 
ultimately stored. Sleeping off after a buzz is a common practice, it can interfere with the sleep cycle, resulting in an increase in anxiety, jumpiness, and irritability the next day, and fatigue the day after that. Although most people take for granted that alcohol impairs memory of events that occur during intoxication, alcohol consumption has furtherreaching effects on memory and learning ability", a Duke University study suggests, "intoxication is produced by temporary impairment of brain receptors key in creating long-term memories in the hippocampus", said Jeff Georgi, a coordinator at the school's Alcohol and Addictions Program. "If you study for four hours...then go drinking, it affects this anchoring process," he told Duke's Chronicle. Alcohol also disrupts sleep, which interferes with long-term memory formation. In addition, young adults seem to have more trouble than older adults learning while drinking, the study suggests. After study subjects drank two drinks in one hour, subjects aged 21 to 24 fared worse on a test of verbal and visual memory than subjects aged 25 to 29.In some cases the linkage between problem drinking and academic performance is profound. Drinking can affect the biological development of young people as well as their school-related achievement and behavior. Serious alcohol use among youth has significant neurological consequences. Alcohol damages areas of the brain responsible for learning and memory, verbal skills and visual-spatial cognition. Diagnosticians often find that these skills in adolescents who drink are deficient in comparison to those who aren't drinking. Scientists know that alcohol problems are tied to lower grades, poor attendance and increases dropout rates. According to Fleming (1992) youths (undergraduates) engage in alcohol use to help them cope with academic stress, negative emotions and make them look mature. Students that use alcohol as a coping mechanism tend to indulge more always in the use of alcohol and most of the time apply defence mechanism by engaging in denial and rationalization. Almost one third of college students admit to having missed a class, and failing a test/project because of alcohol (school Daze, 2000). According to FACTS ON TAP, an organization that specializes in educating college students about the dangers of alcohol consumption, "159,000" of first year undergraduates drops out of school as a result of alcohol and other related drugs.

\section{Statement of Problem}

If you take a closer look at what qualities it takes to have an excellent academic performance, you will know that this are the qualities required to be successful in life, because to have a good academic performance you have to be consistent, determined, focused, then you can have a good academic performance, academic performance reflects your abilities. Success on its own comes with lots of meanings and these meanings varies across individuals, however ones definition of success determines how he dreams and works towards achieving it, nevertheless academic success is the primary and the major step one will likely take in this race, because it is when are educated and have a degree that you will work in a company that gives you some level of happiness and financial stability which in some definition is already a success. Regardless of how one defines success, having a good academic performance will be a boost in achieving it rather than not been educated. Alcohol consumption by students in the university has become unbearable. Not only that alcohol poses danger to health but its negative effect on academic performance. Once in the university, peer group has a strong influence on the students' involvement with alcohol. Students instead of engaging in academic activity spend their precious time in social activity (alcohol). This leads to class misses, failing of tests, rape, unwanted pregnancies, vandalism, drunk driving and other types of crimes.

\section{Hypotheses of the Study}

- There will be a significant positive relationship between alcohol consumption and academic performance.

- There will be a significant difference in academic performance between users and non users of alcohol.

- There will be a significant effect of alcohol consumption on academic performance.

\section{Method Design}

This study which examined the effect of alcohol on academic performance adopted a survey research design. The independent variable is alcohol consumption while the dependent variable is academic performance.

\subsection{Setting}

The study took place in Delta State University (DELSU), Delta State Nigeria. This is a conventional university where students have their independence (freedom). Some live in the hostel while others reside off campus.

\subsection{Participants}

The participants were two hundred undergraduate students of Delta State University (DELSU). Their ages ranges from 15 to 29 years. There were $114(57 \%)$ males and $86(43 \%)$ females.

\subsection{Sampling Technique}

The purposeful sampling method was used to select the participants because of the nature of the study which entails administering questionnaires to undergraduates that indulges in alcohol and those that don't.

\subsection{Instrument}

A structured questionnaire developed by the researcher (Cronbach Alpha coefficient of 0.78 and internal consistency of 0.86) was used to tap relevant information from the participants of the study. The questionnaire consists of different sections with each of the sections collecting 
information on the variable of interest. It comprised A, B, and $\mathrm{C}$. The structure of the questionnaire is outlined below.

\subsection{Section A}

In this section of the questionnaire, demographic information of the participants was captured ranging from age to their department and level of their study.

\subsection{Section B}

This instrument measured the drinking behavior, the quantity and type consumed by the participants.

\subsection{Section $C$}

This instrument measured the academic life and performance (CGPA) of the participants.

\subsection{Procedure for Data Collection}

The researcher randomly selected two hundred undergraduate students of Delta State University Abaraka, Delta state, Nigeria using simple random selection. The respondents cut across age, sex, department and level of study. The criteria for inclusion were; must be an undergraduate student of Delta State University and will be below thirty years of age. The respondents were approached, having acquainted them of the researcher's intention. The respondents consent was duly sought by asking them whether they will participate in the study and signing the consent form. Those who responded in the affirmative participated in the study, while also at the same time requesting them to pick one ballot paper from the basket presented to them. Those who picked 'Yes' written on the card were drawn into the study while those that picked 'No' were excluded from the study. This procedure ensured that every participant was given equal opportunity of participating in the study. Prior to given the questionnaires to them to fill, the researcher instructed them on how they were expected to respond to the statements in the questionnaire (i.e., they should tick on a line in each statement and that the questionnaire should be filled completely as half filled questionnaire would be rendered invalid). Additionally, the participants in the main study were informed that their confidentiality was guaranteed and therefore, they should not write their names on the questionnaires. They were also told albeit individually to mention any areas in the questionnaire they did not comprehend. They admitted that the questionnaire was written in unambiguous language and therefore, they could respond to the statements in the questionnaire almost effortlessly on their own.

\section{Statistical Analysis}

Data generated in this study was analyzed using simple regression analysis, Pearson $\mathrm{r}$, independent $\mathrm{T}$ - test and Anova.

\subsection{Result}

This chapter discusses the analyses and presentation of results. For all the hypotheses tested the minimum level of significance is 0.05 . As stated in chapter three, the independent variable is alcohol consumption and the dependent variable is academic performance.

Table 1. (Level of the participants).

\begin{tabular}{lllll}
\hline Level & Frequency & Percent & Valid percent & Cumulative percent \\
\hline 100 & 24 & 12 & 12 & 12 \\
200 & 28 & 14 & 14 & 26 \\
300 & 82 & 41 & 41 & 67 \\
400 & 42 & 21 & 21 & 88 \\
500 & 24 & 12 & 12 & 100 \\
Total & 200 & 100 & 100 & \\
\hline
\end{tabular}

24 participants (12\%) were 100 level students, 28 participants (14\%) were 200 level students, 82 participants (41\%) were 300 level students, 42 participants (21\%) were 400 level students, 24 participants $(12 \%)$ were 500 level students.

Table 2. (CGPA of the participants).

\begin{tabular}{lllll}
\hline CGPA & Frequency & Percent & Valid percent & Cumulative percent \\
\hline $1.00-2.49$ & 56 & 28 & 28 & 28 \\
$2.50-3.49$ & 94 & 47 & 47 & 75 \\
$3.50-4.49$ & 24 & 12 & 12 & 87 \\
$4.50-5.00$ & 26 & 13 & 13 & 100 \\
Total & 200 & 100 & 100 & \\
\hline
\end{tabular}

56 participants (28\%) have CGPA of 1.00-2.49, 94 participants (47\%) have CGPA of 2.50-3.49, 24 participants (12\%) have CGPA of 3.50-4.49 and 26 participants (13\%) have CGPA of 4.50-5.00. 
Table 3. (Alcohol)

\begin{tabular}{lllll}
\hline Alcohol & Frequency & Percent & Valid percent & Cumulative percent \\
\hline consumers & 170 & 85 & 85 & 85 \\
Non consumers & 30 & 15 & 15 & 100 \\
Total & 200 & 100 & 100 & \\
\hline
\end{tabular}

170 participants (85\%) consume alcohol while 30 participants (15\%) do not.

Table 4. (Etiology of alcohol consumption behavior).

\begin{tabular}{lllll}
\hline Source & Frequency & Percent & Valid percent & Cumulative percent \\
\hline parents & 34 & 20 & 20 & 20 \\
peers & 100 & 59 & 59 & 79 \\
self & 36 & 21 & 21 & 100 \\
total & 100 & 100 & 100 & \\
\hline
\end{tabular}

34 participants (20\%) were influenced by their parents, 100 participants (59\%) were influenced by their peers while 36 participants (21\%) were influenced by nobody.

Table 5. (Quantity consumed in a sitting).

\begin{tabular}{lllll}
\hline No of bottles & frequency & Percent & Valid percent & Cumulative percent \\
\hline $1-2$ & 10 & 6 & 6 & 6 \\
$3-6$ & 110 & 65 & 65 & 71 \\
7 and above & 50 & 29 & 29 & 100 \\
Total & 170 & 100 & 100 & \\
\hline
\end{tabular}

10 participants $(6 \%)$ consumes between 1-2 bottles once, 110 (65\%) participants consumes 3-6 bottles once while 50 participants (29\%) consumes 7 bottles and above once.

Table 6. (Missed class or failed test as a result of hang over).

\begin{tabular}{lllll}
\hline Missed class/failed test & Frequency & Percent & Valid percent & Cumulative percent \\
\hline Yes & 112 & 66 & 66 & 66 \\
No & 58 & 34 & 34 & 100 \\
Total & 170 & 100 & 100 & \\
\hline
\end{tabular}

112 participants (66\%) missed class/failed test due to hang over while 58 (34\%) denied missing class/failing test due to hang over.

Table 7. (Ever been sanctioned in school/home as a result of alcohol use).

\begin{tabular}{lllll}
\hline Sanctioned & Frequency & Percent & Valid percent & Cumulative percent \\
\hline Yes & 158 & 93 & 93 & 93 \\
No & 12 & 7 & 7 & 100 \\
Total & 170 & 100 & 100 & \\
\hline
\end{tabular}

$158(93 \%)$ participants have been sanctioned for the use of alcohol while $12(7 \%)$ participants claim not to have been sanctioned. This is of a grave consequence.

\subsection{Hypotheses Testing}

Hypothesis one states that there will be a significant relationship between alcohol consumption and academic performance.

Table 8. (Summary of correlation coefficient).

\begin{tabular}{lllllll}
\hline Variation & N & DF & Mean & SD & R observed & Significant level \\
\hline Alcohol use & 200 & \multirow{2}{*}{199} & 22.26 & 4.29 & \multirow{2}{*}{$0.74^{*}$} & \multirow{2}{*}{0.05} \\
Academic performance & 200 & & 5.64 & 6.08 & & \\
\hline
\end{tabular}

The result confirmed the hypothesis that there is a significant relationship between alcohol use and academic performance, $\left(\mathrm{R}^{2}=0.74, \mathrm{P}<. \mathrm{O} 5\right)$ 
Hypothesis two states that there will be a significant difference in academic performance between users and non users of alcohol.

Table 9. (Summary of independent $t$ test).

\begin{tabular}{llllll}
\hline Variations & N & DF & Mean & SD & T observed \\
\hline Student alcohol users & 170 & \multirow{2}{*}{198} & 2.18 & 1.29 & \multirow{2}{*}{0.05} \\
Students alcohol non users & 30 & & 3.64 & 0.08 & \multirow{2}{*}{$0.22^{*}$} \\
\hline
\end{tabular}

The result confirms that there is a significant difference in academic performance of students that drink alcohol and those that do not $\left(\mathrm{R}^{2}=12.22, \mathrm{P}<.05\right)$,

Hypothesis three states that there will be a significant effect of alcohol consumption on academic performance.

Table 10. (Regression summary).

\begin{tabular}{lllll}
\hline Model & $\mathbf{R}$ & R square & Adjusted R square & Std. Error of the estimation \\
\hline 1 & .691 & .477 & .448 & 4.070 \\
\hline
\end{tabular}

$47.7 \%$ of the variation in the academic performance could be accounted for by alcohol consumption while $52.3 \%$ represents alcohol consumption measurement error in alcohol consumption and other variables that influence academic performance that were not considered.

Table 11. (Alcohol consumption and academic performance variance).

\begin{tabular}{lllllll}
\hline Model & source & Sum of squares & DF & Mean square & F & Sig. \\
\hline \multirow{2}{*}{1} & Regression & 16.686 & 1 & 16.686 & & \\
& Residual & 792.071 & 199 & 3.729 & 4.474 & .05 \\
& Total & 758.757 & 200 & & \\
\hline
\end{tabular}

The result confirms that there is a significant effect of alcohol consumption on academic performance $\left(R=.691, R^{2}=4.474, P<.05\right)$. The study has recommendations and limitations.

\section{Discussion and Conclusion}

All the hypotheses that were tested in this study were confirmed. It is evident that alcohol consumption influences the academic performance of the consumer (Engs et al., 1996; Perkins, 1992; Presley et al., 1996a,b; Wechsler et al., 1994, 1998, 2000b). . Undergraduates in the universities are no more under the guidance of their parents and they are free to do whatever they choose. This is evident as some undergraduates run mad at the course of their academic sojourn and some even suffer memory loss thereby finding it hard to graduate as their academic performance is always below pass mark (Wechsler et al., 2000b). Some as a result of their background associates with peers that will end up destroying their lives with alcohol because they want to belong among the big boys on campus. This is a serious issue if those who are regarded as future leaders are destroying themselves with alcohol, then how will our future look like. Alcohol-related sexual assault is a common occurrence on college campuses. Although estimates of the incidence and prevalence vary dramatically because different sources use different definitions and many victims are unwilling to report sexual assaults to the police or other authorities, at least 50 percent of college student sexual assaults are associated with alcohol use (Abbey, 1991, 2002; Abbey et al., 1996, 1998; Copenhaver and Grauerholz, 1991; Harrington and Leitenberg, 1994; Koss, 1992; Koss et al., 1987; Miller and Marshall, 1987; Muehlenhard and Linton, 1987; Presley et al., 1997; Tyler et al., 1998). Further, when alcohol is involved, acts meeting the legal definition of rape appear more likely to occur (Ullman et al., 1999).Even aside academic performance when undergraduates misuse alcohol, damage to the campus environment or residence hall-including vomit and litter-are common after effects. (Engs and Hanson, 1994)

\section{Recommendation}

- There will be a continuous awareness program on the dangers of alcohol consumption on the academic performance for undergraduates starting from freshmen to those in their final year.

- Promotional sales by alcohol companies will be prohibited in the higher institutions.

- Drinking joints and bars will not be allowed to operate within or around universities.

- $\quad$ Self esteem training will be carried out periodically, to let the undergraduates understand that alcohol is not a self esteem booster.

- There will be a periodic alcohol level screening in the universities and a stiff penalty for those found wanting so as to deter others.

\section{References}

[1] Arthur Lage, 2007, D.V.M. (617-432-1289), Harvard publication.

[2] Ali, Shoukat, et al. "Factors Contributing to the Students Academic Performance: A Case Study of Islamia University Sub-Campus." American Journal of Educational Research 1.8 (2013): 283-289. 
[3] Brown, S., Tapert, S., Granholm, E. Delis, D. 2000. Neurocognitive Functioning of Adolescents: Effects of Protracted Alcohol Use. Alcoholism: Clinical and Experimental Research. Vol. 24, No. 2: 164-169.

[4] National Household Survey on Drug Abuse Report. 2002. Academic Performance and Youth Substance Abuse. Washington, DC: National Household Survey on Drug Abuse.

[5] Washington Kids Count. 2003. Impact of Peer Substance Use on Middle School Performance in Washington: Summary. Seattle, Washington: University of Washington.

[6] Greenblatt, J. 2000. Patterns of Alcohol Use Among Adolescents and Associations with Emotional and Behavioral Problems. Rockville, MD: Office of Applied Studies Working Paper. Substance Abuse and Mental Health Administration.

[7] National Center on Addiction and Substance Abuse at Columbia University. 2001. Malignant Neglect: Substance Abuse and America's Schools. New York: Columbia University.

[8] Perkins, H. 2002. Surveying the Damage: A Review of Research on Consequences of Alcohol Misuse in College Populations. Journal of Studies on Alcohol. Supplement No. 14: $91-100$.

[9] National Center on Addiction and Substance Abuse at Columbia University. 1994. Rethinking Rites of Passage: Substance Abuse on America's Campuses. New York: Columbia University.

[10] A. O. Ademuya, B. A. Ola, O. O. Aloba, B. M. Mapayi, O. I. Ibigbami, T. A. Adewumi (2007). Nigeria Journal of Psychiatry. Vol.5 (1) pp.5-9.

[11] Odejide, A. O.\& Ohaeri, J. U. (1994).Awareness and drug abuse among patients attending primary facilities in a rural community. Nigerian Medical Journal.26;18-22.

[12] Oshodi,C.O.(1972).Drug dependence and addiction, my studies in Kaduna; Nigerian Journal of Psychiatry. 1 (3) 194203.

[13] Ebitin,N. William \& Adamson A.Taiwo (2005). Neuropsychiatric Hospital Aro, Abeokuta.

[14] Adelaka, M. L., Abiodun, O. A., Imoukhome, Obayan A. O., Oni G. A. \& Ogunremi O.O.(1993). Psychological correlates of Alcohol, Tobacco and Cannabis use. Finding from Nigerian University. Drug and Alcohol Dependence,33,234-256.

[15] Olley. B. O. (2008). Advanced psychopathology note book. University of Ibadan, Ibadan.

[16] Nwobu, I. W.(2011). Nigeria. Same old tale about National I.ID. card. Available at http:// Leadership. ng.nga articles/8652/201. Accessed, 3 July 2012.

[17] Kegite club, University of Ibadan, Ibadan.

[18] Anumonye N., Omoniwa N., \& Adaranijo H.(1977). Excessive Alcohol use and related Problems in Nigeria. Drug and Alcohol Dependence, vol.2,23-30.

[19] Aworemi J. R., Adegoke A. I., Olabode S.O.(2010). Analytical study of the causal factors of road Traffic crashes in south western Nigeria. Educational Research, vol.1 (4) 118-124.

[20] National institute on Alcohol abuse and Alcoholism, (2005) Historical Document.

[21] David Ducthman \& Philip Murphy (2008) Alcohol effect on student performance, Edge hill University. 